\title{
The Procrustes' Bed and Standardization in Education
}

Youngjoo Kim

Oakland University

\section{Procrustes' Bed}

A book of Greek mythology was one of the readings I greatly enjoyed during my college years. I was fascinated by the various legends and stories of gods, heroes, and monsters featured in the book. Now almost twenty years have passed since I read the book. Many details of the stories have slipped away from my memory, and some stories are gone altogether leaving no trace. Yet, there is one story that left an everlasting impression on my mind-the story of Procrustes.

Procrustes was a crook from Attica, who took the lives of many innocent people passing by his fortress gate. Most of his victims were travelers who were new to the area and unfamiliar with him. With disguised hospitality, Procrustes approached travelers passing by his residence and made a generous offer of a free night's stay. Tired from their long walk, travelers usually accepted the offer with gratitude. Unfortunately, none of those who stayed at Procrustes's house left the place alive.

The shadow of death fell on each guest as the night fell. As soon as they were in bed and asleep, Procrustes would tie them tight and measure their height. The unit of the measure Procrustes used was the length of his bed. If the guest was taller than the length of the bed, Procrustes cut off the parts of his limbs that reached over the length of the bed. If the guest was shorter than the bed, he was stretched out until he fit the full length of the bed. This barbarous practice of tortur- 
ing and murdering people by Procrustes continued until he was slain by Theseus, a legendary king of Athens.

Procrutes' killing spree was mindboggling and the bloody images of the murderous story were quite gruesome. What was especially striking about the story, for me, was the insanity of Procrustes deforming human bodies to make them fit the length of his bed. The horrors of Procustes' bed seem synonymous with people trying to fit square pegs into round holes. Sadly, I find the phenomenon of standardization and testing in current national school policies to be strikingly similar to the inhuman practices of Procrustes, in terms of hobbling our students learning in a misguided push for uniformity and standardization.

\section{Standardization: The Procrustean Bed of Education}

Standardization is a unifying education process, providing the same curriculum and expecting the same learning outcomes for all students. This uniform practice of education has been a dominant phenomenon of schooling in the United States over the last two decades. The central philosophy driving standardization in public schools is standards-based accountability, using students' scores on standardized tests as an index of educational progress. These scores are used by policymakers to impose, potentially severe, consequences on school communities showing less progress or failure.

Standards-based accountability, a cardinal principle of the government's efforts in education reform today, began to draw enormous public support when an educational report, A Nation at Risk, was published in 1983. Creating unparalleled repercussions within the political and media arenas, the report posited that the curriculum content offered at public schools was scant and far from substantial, that the quality of education in America was deplorable, that students in the United States were out-performed by their counterparts in other competing industrialized nations, that public education in America was in total disarray, and that public education in the United States would risk the nation being left behind and losing their long-enjoyed leadership in the global economy. The report continued to claim that in order to fix the problem of school ineffectiveness and to overcome the risk the nation faced, an extensive reform in education was needed and that standards-based learning should be the future direction.

Just as the report, A Nation at Risk (1983), was sensational when it was released, the standards-based reform, offered as a panacea for the failures of performance in school education quickly attracted much attention and support. For many Americans fearing falling behind in 
the global competition, the standards-led education was viewed as a momentous alternative. Creating the standards was believed to bring academic rigor to public schools and strengthen their curriculum content by allowing teachers and students to have clear objectives and enable them to engage in focused classroom activities (Eisner, 1995). The appearance of systemic process and the alignment of curricula, instruction, and evaluations using standardized testing with objectives were appealing to the U.S. society in favor of scientific and technological solutions (Eisner, 2005). The idea that we could engineer learning grew in popularity with the public, politicians, and education policymakers. Soon, states began to adopt standards to promote academic excellence, and increasing numbers of states introduced standardized tests to measure student achievement while holding teachers and/or students accountable for educational outcomes.

Standards-based accountability has been broadened and strengthened in the education act of No Child Left Behind (NCLB), authorized into law in 2002. NCLB mandates that states establish grade level standards for curriculum and instruction, and assess students' achievement using standardized tests. According to the Act, students are to be tested in reading and math annually from $3^{\text {rd }}$ to $8^{\text {th }}$ grade years, and once in the $10^{\text {th }}$ and $12^{\text {th }}$ grades. In science, students are tested in their $3^{\text {rd }}, 5^{\text {th }}$, $6^{\text {th }}, 9^{\text {th }}, 10^{\text {th }}$ and $11^{\text {th }}$ years of schooling.

NCLB demands that public schools demonstrate adequate progress on the state test each year and that by 2014 , all students, without exceptions, meet the academic standards of the state. Schools that continue to fall short of these conditions are imposed with corrective measures and ultimately, may be permanently closed unless the measures successfully precipitate student performance up to a preset standard level. If student test scores do not continue to rise annually, the students will be transferred to other schools, while the school will be reconstituted and all teachers and staff will lose their positions regardless of tenure or worth.

The critical role of NCLB is likely to remain in tact for the most part during the Obama administration, and standards-based accountability seemingly will continue to characterize public education for the coming years, as revealed at the presidential address to the Hispanic Chamber of Commerce on March 10, 2009. At that address, President Obama urged that states create "tougher, clearer" uniform standards expecting more from our students, proposing to "make No Child Left Behind live up to its name." He also made it clear that teachers would be held accountable for students' learning outcomes, noting that teachers whose students demonstrate achievement improvement are going to have monetary rewards while "poor teachers" will be fired. 
Standards-based reforms have developed deep roots in American schools since its entry into the education community. Studies have been conducted analyzing the efficacy of standards-based reforms in the students' learning process. Research findings have been mixed on whether it actually enhances educational quality and student achievement as anticipated. While some studies suggest that the test-based accountability has a positive effect on student learning (Carnoy \& Loeb, 2002; Hanushek \& Raymond, 2005; Peterson \& West, 2003), other research studies claim that test-driven accountability is ineffective in advancing students' achievement (Amrein \& Berliner, 2002, 2003; Nichols \& Berliner, 2008). Additionally, the unfriendly, competitive, and stressful environments promoted by standardized learning and assessment programs tend to drive students away from schools, further increasing their dropout rate (Amrein \& Berliner, 2003; Hong \& Youngs, 2008; Jacob, 2001).

Considering the differing findings of the various studies, it may be premature to conclude if standards-driven accountability is effective in improving student performance. Despite the absence of conclusive statistical validation, however, the education reform model of standards, coupled with high-stakes tests as its predominant assessment tool, continue to hold favor with policymakers. More troublesome is the realization that the standards policies are revealing several serious by-products. Many critics have voiced concerns about the effects of the suppression of individuality, the neglect of individual needs, the deculturalization of the underrepresented, and the possible underdevelopment of the mind. It is important that we consider and discuss these concerns to better evaluate the impact of the standards-based philosophy on learners.

\section{Suppressing Individuality}

Existentialists that pursue questions of who humans are and what it means to live as humans believe that "existence precedes essence" (Sartre, 1957, p. 13). That is, who we are is not predetermined, and we are the results of the choices we make and the way we lead our lives. What is implied in the notion is that we are unbounded creatures with unlimited possibilities for our future. Each individual is free to choose and is unique in tastes, pursuits, and the purpose and meaning of life. These choices decide the course of the road he/she paves and thus, defines/shapes the individual. What naturally occurs from such a route of creative formation of human essence is diversity; discretion and variety of thought and action, an indispensable trait in evolving cultures.

Just as no two persons' fingerprints are identical, similarly, no two people have the same personalities. Buber acknowledges such human 
distinctiveness as existential essence when he says that every person is born to be a particular individual who "represents something new, something that never existed before, something original and unique" (Buber, 1964, p. 16). The idiosyncrasies each individual possesses suggest a distinct, unique perspective and thus, offer diverse contributions bringing novelty to the world.

Unfortunately, standards-driven accountability has little tolerance for differences in the process and outcome of education. Nor does it encourage individual students to develop unique characters and viewpoints. Rather, it diminishes their distinctiveness as it focuses on producing a mass of average people with similar knowledge and values.

According to Sleet and Stillman (2005), "the standards are largely content driven" (p. 41), stipulating a base of knowledge for students to obtain. Knowledge is an individual's representation of the true state of the world, and it is context-dependent, as truth is socially, culturally, and historically situated and conditioned. Knowledge is not only a product resulting from an individual's interaction with an interpretation of the world, but also reflects the view, values, thinking pattern, and reasoning employed in the process of the knowledge production. Once such knowledge is obtained, it functions as a reference for future decisions on what is important and right, what to value and teach, who to become, and how to live and behave. In this sense, knowledge that is value-laden and informative to our thoughts and actions introduces us to new perspectives and different ways of relating to the world and in time and helps to generate new knowledge. Advancement of individuality and creativity demands that students must be exposed to a wide spectrum of ideas and various ways of being, while being encouraged to establish their own unique relationship with and vision of the world. Unfortunately, the standards demarcate elements and events that constitute curriculum and thus, set the limits of the scale and scope of educational experiences.

Furthermore, when coupled with accountability, the standards hobble our students with a one-size-fits-all frame of thoughts and knowledge rather than promoting variation. In the standards-based accountability schema that uses standardized test scores as an index of the quality of education, there is an imposed notion of truth. Students are pressed to accept the test driven lessons as knowledge while simultaneously either being discouraged from alternatives or given none. This incurs the phenomenological control of students' development, singularizing their perceptions and thinking while bleaching out ingenuity and innovation. The end results are dwindled imaginations, limited choices, underdeveloped potentials, and the loss of creativity. This must be seen 
as a failure to accomplish the task of developing students ready to pursue their own goals and create their own essence as free existential beings.

\section{Deculturalizing and Disempowering the Underrepresented}

From the perspective of critical theorists, the standards-based practices that supply a fixed set of knowledge, standardized testing, and a policy of punishment and reward aim to shape the minds of students to fit the norms suggested in the standards. This homogenization opposes diversification and creates problems of deculturalization and disempowerment of minority cultures and viewpoints, forcing them to assimilate into the knowledge and values of the dominant culture.

Forbes (2000) examined the standards applied to schools in California and concluded that they are "heavily favoring White males of U.S. origin," (p. 20) and speak for an elite upper-class ideology. For instance, California history standards center mainly on stories of the European-Americans, while the history and culture of minorities that first settled, established its first communities, and contributed to its culture are neglected to a great extent. Even when the underrepresented people are included in the history standards, the focus is not on acknowledging their roots or the contributions they have made to the history of the United States. Rather, students are taught of their defeat and subjugation or of their debt to the American culture. The history standards for California schools tend to lead students in the state to believe that success in America is mainly a result of the labor and struggles of European-based cultures. The standards dismiss the contributions of other minority cultures as inconsequential and not germane to learning. The claim that the curriculum content of public schools in California is biased towards dominant White males has been supported by other studies published in later years (Sleeter, 2002; Sleeter \& Stillman, 2005), showing a clear example of inequity in education.

The predominance of White, male, mainstream perspectives is especially striking and problematic for California considering the state is the most racially diverse in the nation and more than half of its population is non-White. This problem, however, is not particular to the state of California. The predominance of the dominant culture group's perspective in American education is widespread. By creating and defining the standards, their interpretations of the world are taught as the truth and official knowledge (Apple, 2000). In fact, according to Spring (2007), it has been a tradition of American education to teach the knowledge and lore of the dominant culture, advocating its superiority while minimizing and dismissing the contributions of other cultural groups. This tradition 
of authorizing the mainstream scholarship while downplaying that of the underrepresented continues to survive in present days' standardsbased curricula and test materials. The standards movement further enhances the process of deculturalization overlaying the culture of the dominant onto the cultures of the underrepresented.

Critical observers of education such as Forbes (2000) and Spring (2007) have noted that the preeminence of the dominant culture's knowledge is not something that accidentally happens. Rather, it is a result of deliberate efforts to engineer acculturation. School is an institution that the haves in power depend upon to maintain and legitimize their status. In so doing, it is important to teach people to view the society from the perspective of the privileged: class stratification is a natural part of a society; the culture of the upper class is superior to those of other groups; the privileged are more capable than the deprived; and the powerful have the right to make the rules.

The control of official knowledge by the upper class is plainly and painfully unjust and unfair. While helpful in maintaining their power in society, it places others at a disadvantage and does a great disservice to learners, particularly those from marginalized minority backgrounds. These underrepresented students, hobbled by outsider status and knowledge based on scholarship from minority perspectives, often find schools to be difficult to comprehend and unsympathetic to their learning needs. Further staggered by language and culture difference, they often find it difficult to navigate academic success in school. The absence of their root beliefs and cultural past from the school curriculum deprives them of a sense of authenticity that comes from the confidence of knowing who they are. The denigration of their culture leads them to question the validity of their caliber and consequently their value to society.

The curricular exclusion of minorities, misfits, and underprivileged students can contribute to their experiencing "moments of disequilibrium, like looking into a mirror and seeing nothing" (Rich, 1986, p. 119, as cited in Bohn \& Sleeter, 2001). What is experienced is the feeling of alienation and rejection and the diminution of self. When there exists disconnectedness between in-school and out-of-school worlds, students' affirmation of self is not achieved and their innate power and personal drive dissipates.

\section{Under-developing the Mind}

Another problem of standards-driven accountability and resulting standardization of education processes is that they inhibit the mind from developing to its fullest potential. Cognitive development requires 
students to be exposed to the broadest appropriate stimuli and the richest intellectual experiences. However, the rigid structures of standards discourage teachers and students from participating in the thoughtful exploration of a ide spectrum of opinions and ideas. The test schedule does not allow time for teachers and students to participate in educational experiences outside the boundary of the handed-down curriculum (Sleeter \& Stillman, 2005).

Moreover, standards-driven accountability deemphasizes and devitalizes important intellectual and aesthetic faculties such as art, music, poetry, and creative writing. Within the current accountability system, school communities are rated for their educational productivity based on students' performance on math, science, and reading tests. Even though these high-stakes tests provide only a brief snapshot of student performance, failure can carry severe consequences for schools that range from probation status to loss of jobs and eventual restructuring or closure of the school. When the stakes are high, "what is measured is treasured" (Pederson, 2007). Teachers are spending increasing classroom hours concentrating on limited subject matters such as math, science, and reading, particularly focusing on what is predicted to be on tests. At the same time, subject matters that are not tested such as art, music, social studies, culture studies, etc. are ignored and dismissed as they become victims to the loss of class time and the cost of test preparation materials (Eisner, 2001; Pederson, 2007), although these subjects make up the fabric of our society's knowledge and as such, are necessary for the understanding of our learning. This imbalance in curriculum fails to help students develop other dimensions of understanding aside from math- and science-oriented rational thinking. They will be less prepared to explore eventful surprises of life or to employ relational thinking in understanding their surrounding world.

Finally, the shaping of the docile and uncritical mind is another problem the current standards-based education generates. Within the educational schema that holds schools accountable for students' performance on tests, the focus is naturally on raising test scores. When the focus is on high performance, intellectual exchanges between teachers and students diminish while old mechanical methods of learning and knowledge retention are relied upon. Critical questions about the value and authenticity of ideas and beliefs are rarely posed for students to deliberate. The important question of what is worth knowing and experiencing (Schubert, 1991) is lost from the curriculum discourse in the classroom. What is encouraged, instead, is students' compliance with the top-down curriculum imposed on them and a blind acceptance of the official knowledge as "truth," with no guaranteed veracity. 
An unfortunate consequence of the heightened pressure for acquiring a fixed set of curriculum content is the return of the often-overused tools of memorizing, drilling, and worksheet practices as classroom activities. Quite a few standardized test items are designed to elicit memory-based content knowledge. This inevitably causes classes to focus on a thin veneer of a broad span of topics. Rather than being involved in critical analysis and in-depth discussions of their topics, students are taught to achieve an understanding of curriculum material that is a mile wide and an inch deep. In addition, as the standards-driven reforms control the methods of assessing students' learning, selecting a correct answer among limited options on a timed test is regarded as the only valid way of demonstrating knowledge. What is crucial for high scores on such tests is an ability to make the most of the time given for each question, which precludes in-depth thinking in the first place. It is little wonder that many the high scorers on standardized tests tend to be flash thinkers (Hall, Larry, \& Gupton, 1995, as cited in Kohn, 2000).

As well, the high-stakes for teachers and students involved in standardized testing lead classrooms to spend an increasing amount of time in test preparation, practicing, drilling, and solving problems predicted to be on the state's standardized tests. Learning time is lost to administering mock-tests to familiarize students with the state's test format (Pederson, 2007). In a practice focused more on getting correct answers than understanding, test preparations are devoted to routine drilling of formulae and procedures for problem solving rather than cultivating cognitive skills set forth in the standards. The test-based activities tend to be dominant in low-performing, poor, urban schools facing heavy pressure to raise test scores. Ironically, it seems that those who need authentic learning the most are more likely to be supplied with exiguous instructional practices.

When students are given a tightly prepackaged curriculum rather than provided with the chance to play a role in creating their own course of learning, we stifle their creativity and cripple their learning skills. In an education system obsessed with correct answers to test items rather than meaningful learning, the bulk of classroom activities will continue to consist of shoddy practices of drilling, memorizing, and regurgitating data. Students are taught to take passive roles and are given no ownership of their own education. It is unsurprising that "young people feel so little connection to their learning environment" (Dewey, 1989, p. 159). Understandably, people are unable to engage in intellectual discourse on important social issues after spending a decade or longer avoiding critical thinking or thoughtful dialogue (Glass, 2003). They are ready to believe what they are told, rather than questioning, analyzing, and deciding for 
themselves. Surely, such unexamined, uncurious learning will contribute little to the advancement of an informed and active democracy.

\section{Concluding Remarks}

A non-dynamic uniformity in education is the predictable outcome of standards-based education reform. The assumption of expecting the same output by providing the same input disregards the uniqueness of individual students. For me, this closely resembles Procrustes' idea of making everyone fit the length of his bed-a parallel exists between the phenomena of diminishing individuality, deculturalizing the underrepresented by imposing knowledge of the dominant, and stifling creativity, and the bizarre amputating and stretching of limbs to fit a bed. Just as Procrustes ruined the body resulting in death, so does standardization oppress minds and prevent individuals from "naming the world" (Freire, 1970, p. 69) and using their own lens and critical consciousness to reason.

Considering the magnitude of negative effects stemming from the standards-based education discussed above, the educational efficacy of this one-size-fits-all approach is questionable. For me, it is unwise to set and impose standards on students without regard to their native culture and learning. Forcing students to accept an official curriculum of prescribed knowledge and culture is as absurd as changing people to fit one bed.

I began this essay with reflections of the story of Procrustes, and that would be a fitting place to conclude my comments. The stories of torture and death by Procrustes continued until Theseus, a hero from Athens, fought and destroyed Procrustes and his bed. Just as Theseus's courageous act put an end to Procrustes' wrongdoings, what is needed today in education is leadership in school communities dedicated to end the cognitive deforming and intellectually stunting practices of the current standards-driven system. As Theseus' actions began with the notion of justice, our efforts to follow Theseus' example need to begin with an understanding that effective education must seek to expand inquisitiveness, raise curiosity and excite imaginations and that a fruitful model for such education would be to help individuals develop into unique beings and enhance their "productive idiosyncrasy" (Eisner, 2005 , p. 16), not to apply a cookie cutter mindset to our learning goals. Equality in education means providing equal opportunities to explore who they are and who they want to become, instead of restricting access to approved knowledge. It should also be remembered that our efforts to reform will be successful only when the notions of self-authentification, 
increased diversity, and participatory democracy are at the core of the curricula.

\section{References}

Amrein, A., \& Berliner, D. (2002). High-stakes testing and student learning. Education Policy Analysis Archives, 10(18).

Amrein, A., \& Berliner, D. (2003). The effects of high-stakes testing on student motivation and learning. Educational Leadership, 60(5), 32-38.

Apple, M. (2000). Official knowledge: Democratic education in a conservative age $\left(2^{\text {nd }}\right.$ ed.). New York: Routledge.

Bohn, A., \& Sleeter, C. (2001). Will multicultural education survive the standards movement? Phi Delta Kappan, 66(5), 17-24.

Buber, M. (1964). The way of man: According to the teaching of Hasidism. New York: Citadel Press.

Carnoy, M., \& Loeb, S. (2002). Does external accountability affect student outcomes?: A Cross-state analysis. Educational Evaluation and Policy Analysis, 24(4), 305-331.

Dewey, J. (1989). Education for a changing social order. In J. A. Boydston (Ed.) John Dewey: The later works, 1925-1953, Volume 9: 1933-1934. (First published in Peabody Reflector and Alumni News, 7 (April 1934): 123-24, 142-143, from an address on 23 February 1934 to the American Association of Teachers Colleges in Cleveland, Ohio).

Diamond, J., \& Spillane, J. (2004). High-stakes accountability in urban elementary schools: Challenging or reproducing inequality? Teachers College Record, 106(6), 1145-1176.

Eisner, E. (1995). Standards for American schools: Help or hindrance. Phi Delta Kappan, 76(10), 758-764.

Eisner, E. (2001). What does it mean to say a school is doing well? Phi Delta Kappan, 82(5), 367-372.

Eisner, E. (2005). Back to whole. Educational Leadership, 63(1), 14-18.

Forbes, J. (2000). The new assimilation movement: Standards, tests, and AngloAmerican supremacy. Journal of American Indian Education, 39(2), 7-27.

Freire, P. (1970). Pedagogy of the oppressed. New York: Continuum.

Glass, R. D. (2003). Pluralism, justice, democracy, and education: Conflict and citizenship. Philosophy of Education, 158-166.

Hanushek, E., \& Raymond, M. (2005). Does school accountability lead to improved student performance? Journal of Policy Analysis and Management, 24(2), 297-327.

Hong, W., \& Youngs, P. (2008). Does high-stakes testing increase cultural capital among low-income and racial minority students? Education Policy Analysis Archives, 16(6), 1-21.

Jacob, B. A. (2001). Getting tough? The impact of high school graduation exams. Education Evaluation and Policy Analysis, 23(2), 99-121.

Jacob, B. A. (2003). High stakes in Chicago: Did Chicago's rising test scores reflect genuine academic improvement? Education Next, 3(1), 66-72. 
20 The Procrustes' Bed and Standardization in Education

Kohn, A. (2000). The case against standardized testing: Raising the scores, ruining the schools. Westport, CT: Boynton/Cook.

National Commission on Excellence in Education (NCEE). (1983). A nation at risk: The imperative for Educational Reform. Washington, DC: U.S. Department of Education.

Nichols, S., \& Berliner, D. (2008). Testing the joy out of learning. Educational Leadership, 65(6), 14-18.

Pederson, P. (2007). What is measured is treasured: The impact of the No Child Left Behind Act on nonassessed subjects. Clearing House, 80(6), 287-291.

Peterson, P. E., \& West, M. R. (Eds.). (2003). No Child Left Behind? The politics and practice of school accountability. Washington, DC: Brookings Institution Press.

Sartre, J. (1957). Existentialism and human emotions. New York: Citadel Press.

Schubert, W. (1991). Ten curriculum questions for principals. NASSP Bulletin, 75(532), 1-10.

Sleeter, C. (2002). State curriculum standards and the shaping of student consciousness. Social Justice, 29(4), 8-25.

Sleeter, C., \& Stillman, J. (2005). Standardizing knowledge in a multicultural society. Curriculum Inquiry, 35(1), 27-46.

Spring, J. (2007). Deculturalization and the struggle for equality: A brief history of the education of dominated cultures in the United States (5 $5^{\text {th }}$ ed.). New York: McGraw Hill. 